\title{
ANÁLISE DO ÍNDICE DE QUALIDADE DE ÁGUA NA BACIA DO CÓRREGO DO RIO ACIMA, SÃO JOÃO DEL-REI/MG
}

\author{
Arlon Cândido Ferreira ${ }^{1}$
}

Leonardo Cristian Rocha ${ }^{2}$

Múcio do Amaral Figueiredo ${ }^{3}$

\begin{abstract}
RESUMO
A água é parte integral da dinâmica do planeta e, embora ela seja um recurso renovável, o que vemos é o suprimento de água se esgotando. Sendo assim, é cada vez maior a procura por mananciais para abastecimento da população. Por esse fato, para a determinação da qualidade das águas tem sido adotado um parâmetro para a escolha desses mananciais. Com o surgimento do Índice de Qualidade das Águas (IQA), critérios foram determinados para o estabelecimento da qualidade das águas para abastecimento humano. No Brasil, o IQA é estabelecido pela Portaria $\mathrm{n}^{\circ}$ 518/05 do Ministério da Saúde. Dessa forma, este trabalho tem como objetivo avaliar o IQA nos pontos de coleta do córrego Rio Acima através de análises físico-químicas e bacteriológicas com o intuito de verificar e de identificar possíveis fontes poluidoras que contribuem para a degradação deste manancial. Após a coleta e realização das análises, foi comprovado que há parâmetros acima do permitido, tanto na captação da represa do 14 quanto na capitação do córrego do Rio Acima. Sem o tratamento adequado, essas substâncias se tornam vetores de várias doenças. Após o tratamento, verificou-se a eliminação dos riscos e a padronização. Sendo assim, o tratamento se mostrou eficiente, porém ainda é necessária uma maior harmonia entre o homem e os recursos hídricos, bem como a necessidade de respeitar os limites de mata ciliar, fazendo uso adequado do solo e conscientizando os fazendeiros e a população no entorno, além da realização de projetos e de campanhas que vise a preservação.
\end{abstract}

PALAVRAS-CHAVE: Bacia Hidrográfica; Índice de Qualidade de Água; Córrego do Rio Acima.

\section{ANALYSIS OF WATER QUALITY INDEX IN BOWL UP RIVER STREAM, SÃO JOÃO DEL REI / MG}

\footnotetext{
${ }^{1}$ Mestrando do Programa de Pós-Graduação em Geografia, UFSJ, arloncf@gmail.com

${ }^{2}$ Professor Doutor do Programa de Pós-Graduação em Geografia, UFSJ, rochageo@ufsj.edu.br

${ }^{3}$ Professor Doutor do Programa de Pós-Graduação em Geografia, UFSJ, muciofigueiredo@ufsj.edu.br
} 
Revista Nacional de

Gerenciamento de Cidades

\begin{abstract}
Water is an integral part of the dynamic of the planet and, although it is a renewable resource, what we see is the water supply running out. Thus, it is increasing the demand for water sources to supply the population. By this fact, to the determination of water quality has been adopted a parameter for choosing these sources. With the emergence of the Water Quality Index (WQI), it was determined criteria for the establishment of water quality for human consumption. In Brazil, the WQI is established by Decree 518/05 in the Ministry of Health. Thus, this study aims to evaluate the WQI at collection points Stream Rio Up through physical-chemical and bacteriological analyzes in order to check and to identify possible pollution sources that contribute to the degradation of this spring. After collection and analysis performance, it was proved that there are above the allowed parameters, both in the capture of the 14 dam and in the income of the stream "Rio Acima". Without an appropriate treatment, these substances become vectors of various diseases. After treatment, there was the elimination of risks and standardization. Thus, the treatment proved effective, but it is still necessary greater harmony between man and water resources and the need to respect the boundaries of riparian forest, doing an appropriate land use and also to raise farmers and people in the vicinity, as well as projects and campaigns that aim the preservation.
\end{abstract}

KEY-WORDS: Basin River; Water Quality Index;Stream "Rio Acima".

\title{
ANÁLISIS DEL ÍNDICE DE CALIDAD DEL AGUA EN CORRIENTE BOWL RÍO ARRIBA, SÃO JOÃO DEL REI / MG
}

\begin{abstract}
RESUMEN
El agua es una parte integral de la dinámica del planeta $y$, aunque es um recurso renovable, lo que vemos es el suministro de agua corriente. Por lo tanto, está aumentando la demanda de fuentes de agua para abastecer a la población. Por este hecho, para la determinación de la calidad del agua se ha adoptada un parámetros para la elección de estas fuentes. Com la aparición del Índice de Calidad del Agua (ICA), se determinaron los criterios para el establecimiento de la calidad del agua para consumo humano. En Brasil, el ICA es establecido por el Decreto 518/05 del Ministerio de Salud. Por lo tanto, este estúdio tiene como objetivo evaluar el ICA em los puntos de recogida de Corriente Rio Acima a través de los análisis bacteriológicos y físico-químico com el fin de verificar e identificar posibles fuentes de contaminación que contribuyen a la degradación de esta primavera. Después de recoger y llevar a cabo los análisis, se comprobó que no está por encima de los parámetros permitidos, tanto en el aumento del 14 como la capitación de la presa del Rio Acima. Sin tratamiento, estas sustancias se convierten en vectores de diversas enfermedades. Después del tratamiento, no es la eliminación de los riesgos y la normalización. Por lo tanto, el tratamiento resultó eficaz, pero una mayor armonía entre el hombre y los recursos hídricos, y la necesidad de respetar los límites de los bosques de ribera sigue siendo necesaria, uso de la tierra adecuada y la educación de los agricultores y la población em los alrededores además de llevar a cabo proyectos y acciones encaminadas a la preservación.
\end{abstract}

PALABRAS CLAVE: Cuenca; Índice de Calidad del Agua; Corriente del Rio Acima. 


\section{Revista Nacional de}

\section{INTRODUÇÃO}

A crescente expansão demográfica e industrial observada nas últimas décadas trouxe como consequência o comprometimento das águas dos rios, lagos e reservatórios (SILVEIRA E GUANDIQUE, 2006). A água é provavelmente o único recurso natural que diz respeito a todos os aspectos da civilização humana, sendo o uso para o abastecimento humano prioritário e suas características refletem na qualidade de vida da sociedade.

Segundo Teixeira et. al., (2001), o Brasil é um país privilegiado, uma vez que recentes estimativas indicam que aqui correm $53 \%$ da água doce da América do Sul e $12 \%$ da vazão total mundial dos rios. Para melhor gerenciamento dos recursos hídricos, a partir da Lei 9.433/97, definiu-se a bacia hidrográfica como unidade de planejamento, sendo a Divisão Hidrográfica Nacional (DHN) instituída pela Resolução do $\mathrm{CNRH} \mathrm{n}^{\circ} 32$ de 15 de outubro de 2003, sendo o Brasil composto por 12 grandes Bacias Hidrográficas (ANA, 2014).

A partir da utilização das bacias hidrográficas como unidade de gestão, esse gerenciamento, prevê uma visão integrada dos processos hidrológicos com os condicionantes geomorfológicos, climáticos, geológicos, biológicos e antrópicos. Sendo assim, o monitoramento das águas dos mananciais para o abastecimento público é uma ferramenta importante tanto para o controle da qualidade hídrica quanto para as decisões corretivas e preventivas (BOLLMANN, 2003).

A partir de um estudo realizado em 1970 pela National Sanitation Foundation (NSF), a Companhia do Estado de São Paulo (CETESP) adaptou e desenvolveu o Índice de Qualidade das Águas (IQA) (PERINI et. al., 2012). Esse índice vem sendo utilizado para avaliar a qualidade das águas não só do estado de São Paulo como de outros estados (SAAD et. al., 2007). No Brasil, o IQA é estabelecido pela Portaria $n^{\circ} 518 / 05$ do Ministério da Saúde. 


\section{Revista Nacional de}

Dessa forma, este trabalho tem como objetivo avaliar a qualidade das águas na Bacia Hidrográfica do Córrego do Rio Acima onde a água é captada, tratada na Estação de Tratamento de Água (ETA) e fornecida à população. Serão comparadas análises realizadas em amostras coletadas in natura e em águas que sofreram tratamento para ser distribuídas à população.

\section{OBJETIVOS}

O objetivo deste artigo é avaliar o IQA nos pontos de coleta do córrego Rio Acima através de análises físico-químicas e bacteriológicas com o intuito de verificar e identificar, assim, as possíveis fontes poluidoras que podem, de forma significativa, contribuir para a degradação deste manancial.

\section{METODOLOGIA}

A Bacia do Córrego do Rio Acima está localizada no município de São João del-Rei, cidade localizada na região do Campos das Vertentes, Minas Gerais (Figura 01). O Córrego do Rio Acima tem sua foz no Córrego do Lenheiro, um dos afluentes da margem esquerda do Rio das Mortes que deságua no Rio Grande. 
Revista Nacional de

Gerenciamento de Cidades

Figura 01: Mapa de localização da Bacia Hidrográfica do Córrego do Rio Acima.

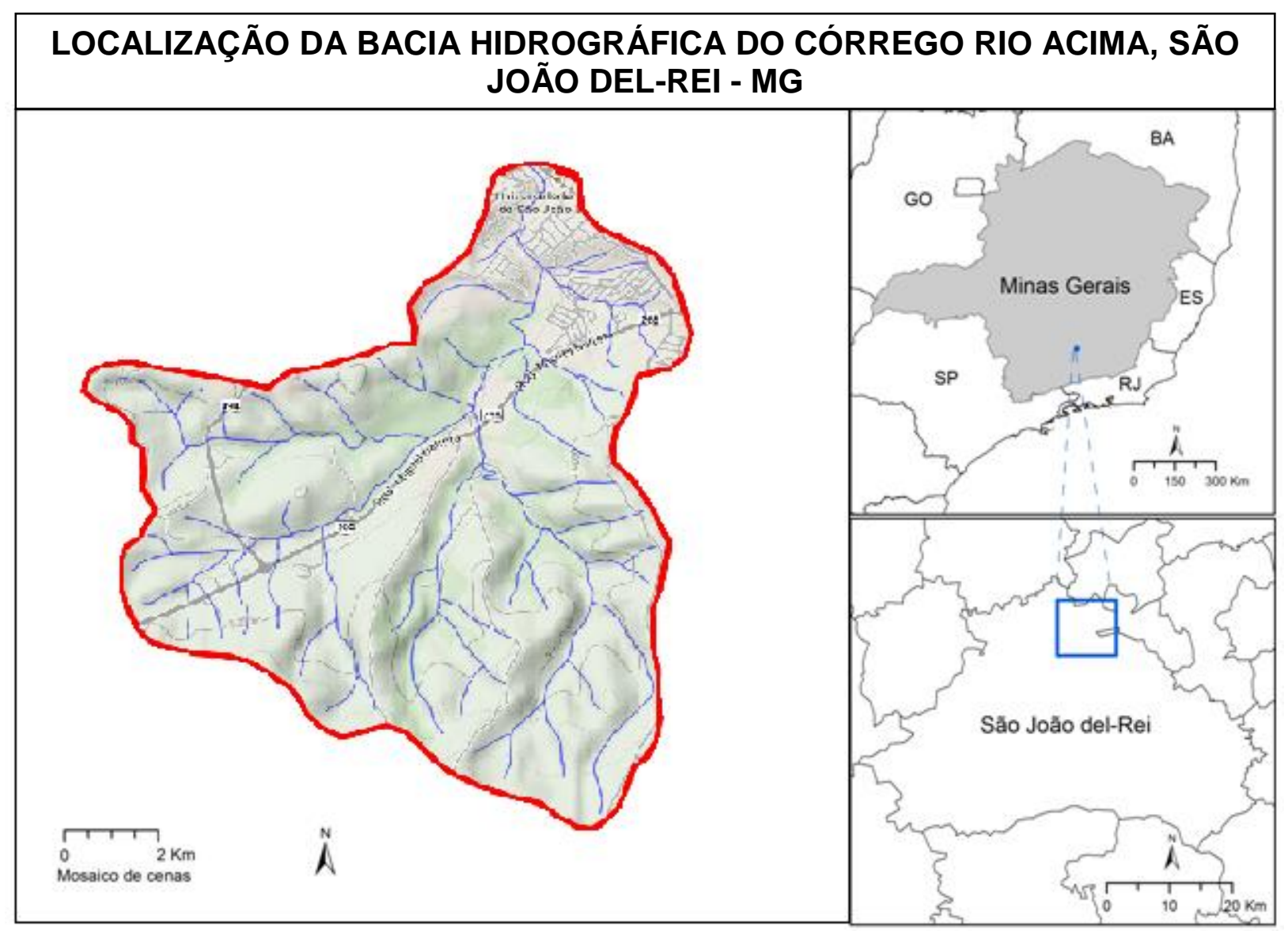

Fonte: Dados do Autor.

\subsection{Clima}

Segundo a classificação de Koppen, o clima da região é do tipo Cwb com duas estações bem definidas: período seco com deficiência hídrica no período de março a setembro e período chuvoso de outubro a março. A precipitação anual está em torno de $1.400 \mathrm{~mm}$, sendo sua temperatura média de cerca de $19^{\circ} \mathrm{C}$. 


\subsection{Geologia}

A região está situada na porção central da Província Geotectônica da Mantiqueira constituída por rochas de idade Arqueana, rochas tais que foram intensamente reestruturadas durante o período Proterozóico Superior (MACIEL JÚNIOR, 2001).

\subsection{Geomorfologia}

A região pertence ao domínio morfoestrutural "Remanescentes de Cadeias Dobradas" e apresenta colinas com topos convexos a tubulares e encostas suavizadas que se intercalam com cristas suavizadas, sendo frequente a presença de voçorocas. A tendência das drenagens da região e para a densidade média é baixa e o seu relevo possui um padrão de dessecação homogêneo (BARUQUI, 2006).

\subsection{Pedologia}

Segundo Baruqui (2006), a região onde se localiza a Bacia Hidrográfica é constituída principalmente por Latossolos e por Cambissolos.

O padrão de drenagem que a disposição dos canais em uma Bacia é dendrítico, conforme Christofoletti (1980). Esse padrão tem como característica nenhuma orientação evidente dos canais com falta de controle estrutural em rochas de resistência uniforme (Figura 02). 


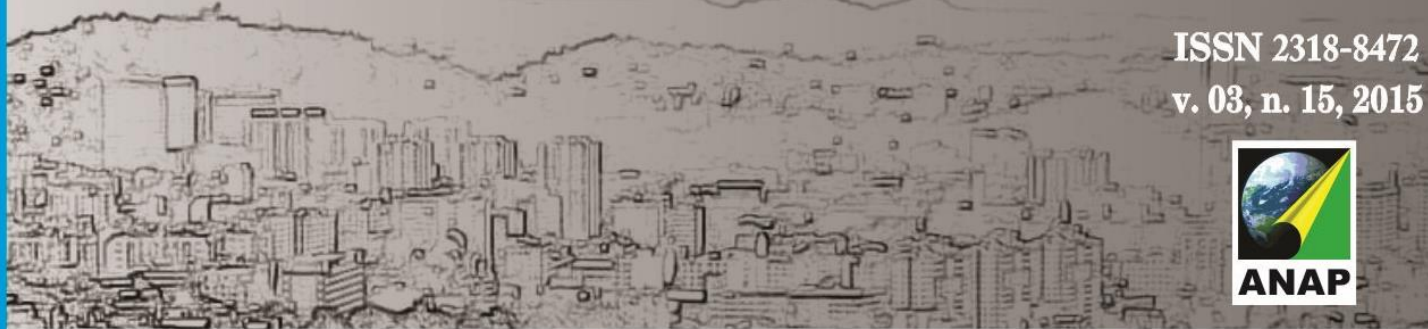

Revista Nacional de Gerenciamento de Cidades

Figura 02: Mapa das Linhas de Drenagem da Bacia Hidrográfica do Córrego do Rio Acima.

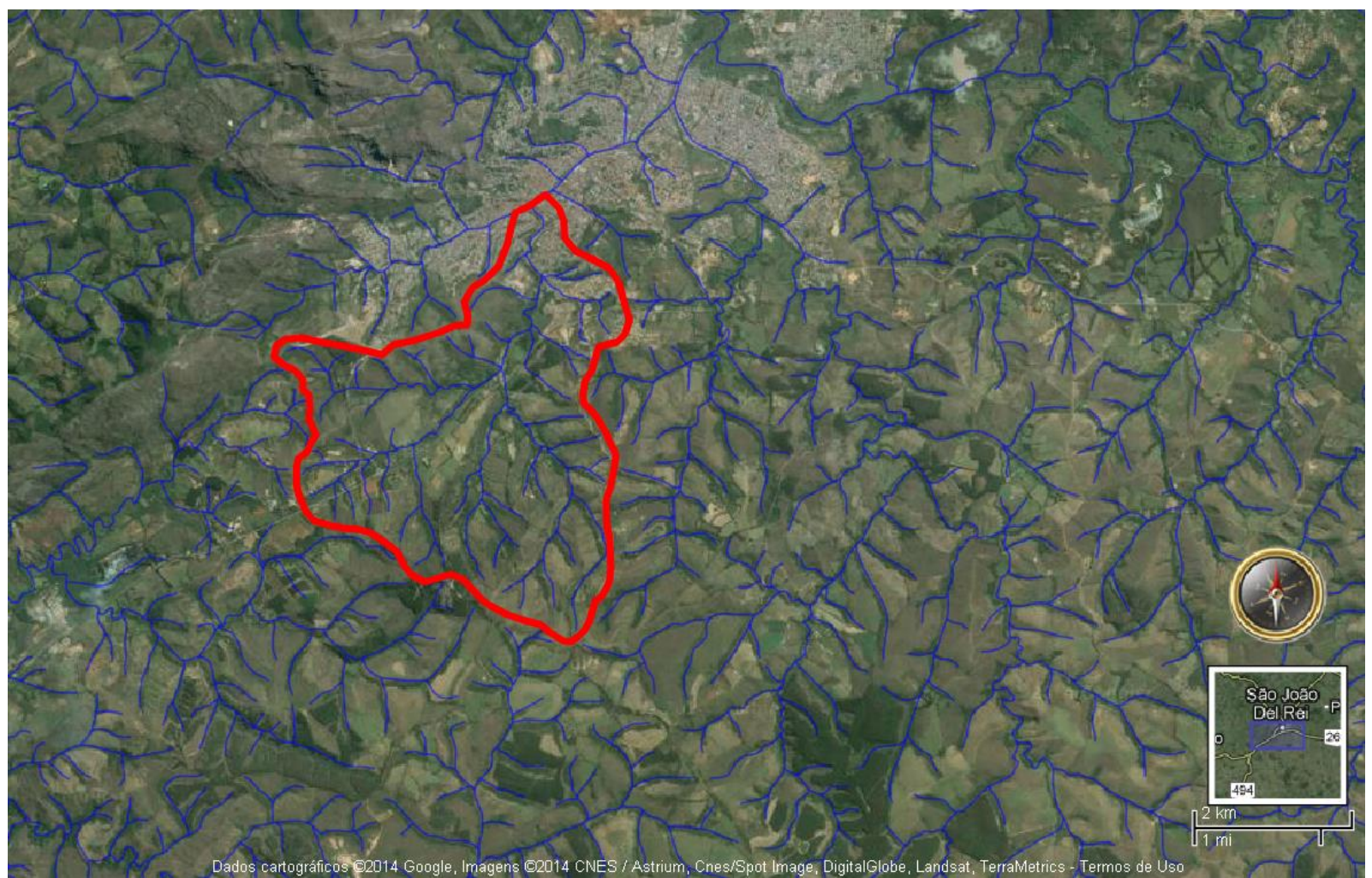

Fonte: Adaptado do Zoneamento Econômico-Ecológico do Estado de Minas Gerais.

A Bacia do córrego do Rio Acima possui 2 (dois) pontos de coleta de água bruta (Córrego do Rio Acima e Represa do 14) e 2 (duas) estações de tratamento de água (ETA Rio Acima e ETA Bonfim) as quais abastecem os bairros São Caetano, Guarda-Mor,Vila São José, Residencial São José, Lenheiro, Vila São Bento, Barro Preto, Alvorada, Gameleiras, parte Alta do Maria Alves Barbosa e Bonfim.

Para a realização desse trabalho, as coletas foram realizadas em 4 (quatro) pontos diferentes, sendo duas de água bruta e duas de água tratada. As águas brutas foram coletadas na Represa do 14 e no ponto de Captação do Córrego do Rio Acima. As águas tratadas foram coletadas na ETA Rio Acima, que trata a água proveniente do Córrego do Rio Acima, e na ETA Bonfim, que trata a água proveniente da Represa do 14 (Figura 03). 


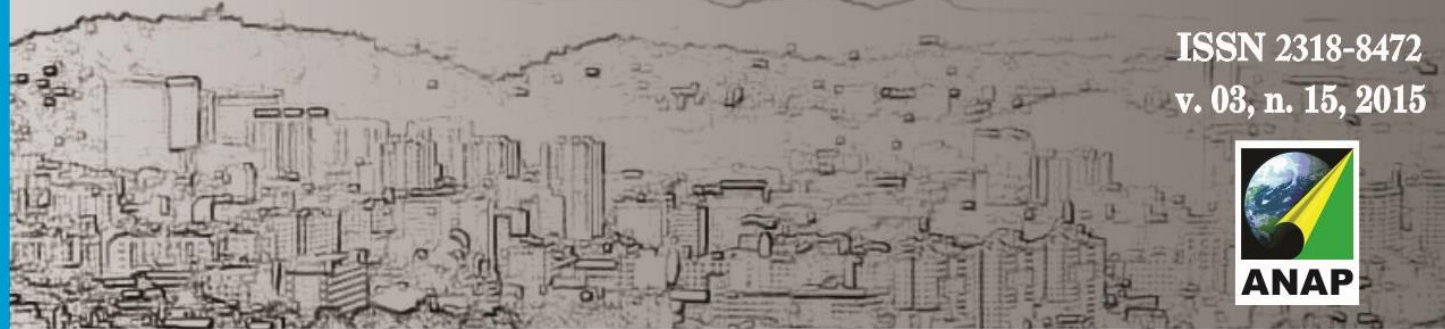

Revista Nacional de Gerenciamento de Cidades

Figura 03: Mapa de localização das coletas na Bacia Hidrográfica do Córrego do Rio Acima.

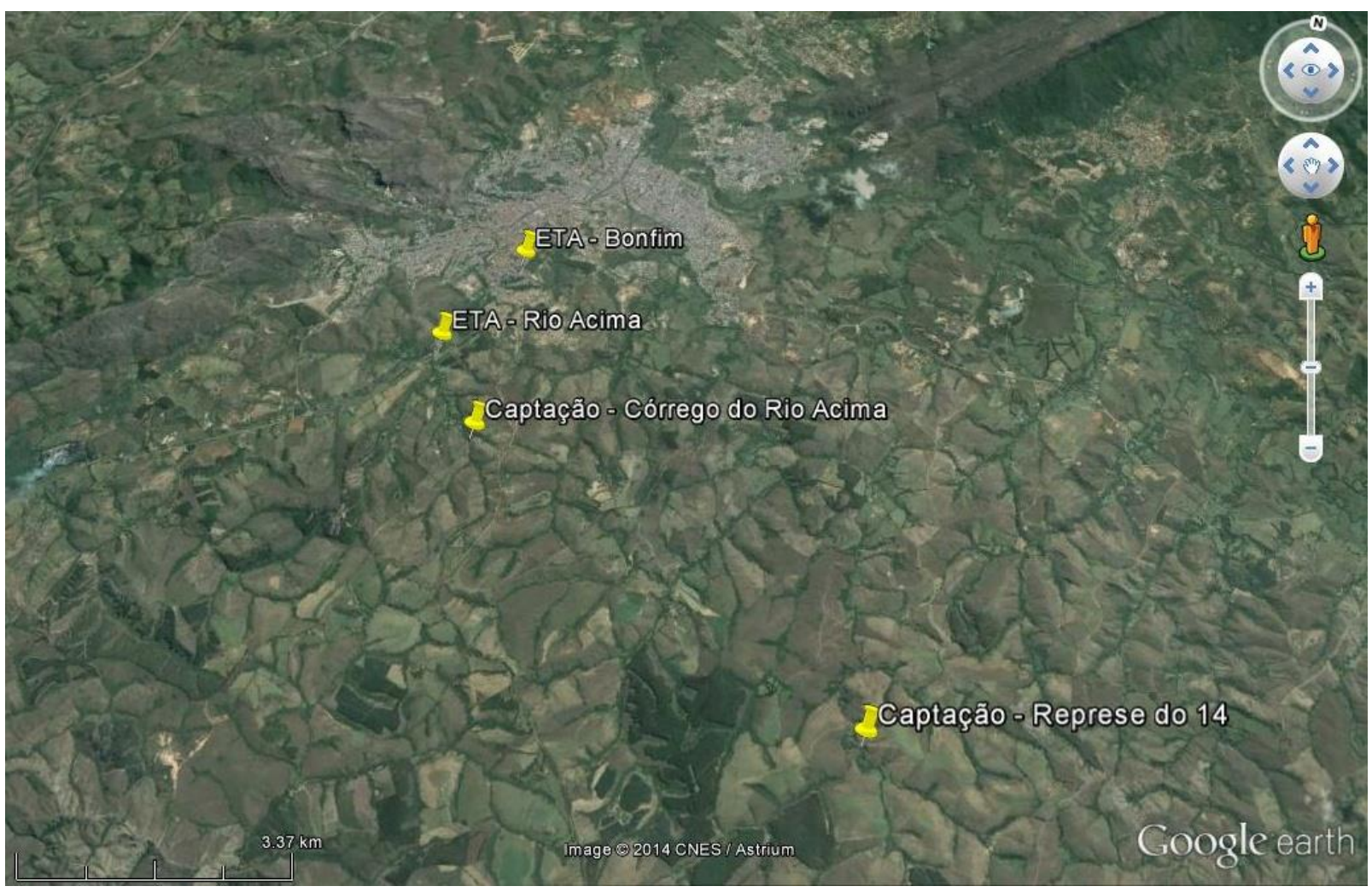

Fonte: Google Earth.

As coletas das amostras de águas foram realizadas por uma Laboratório contratado pelo Departamento Autônomo Municipal de Água e Esgoto de São João del-Rei (DAMAE) em Novembro de 2013. As análises bacteriológicas e físicoquímicas das amostras de água dos mananciais foram realizadas pelo mesmo laboratório que efetuou as coletas, tendo como parâmetro de referência a portaria do Ministério da Saúde 2.914 de 12 de Dezembro de 2011. Para a retirada, a preservação e o transporte das amostras, foram utilizados os procedimentos do POP 05.07 e o IT SeCOL002 para Plano de Amostragem. 


\section{Revista Nacional de Gerenciamento de Cidades}

\section{RESULTADOS}

Após a coleta e realização das analises laboratoriais, ficou comprovado que estão em desacordo como os limites da portaria 2.914 do Ministério da Saúde os seguinte parâmetros dos pontos de coleta (tabelas 01 e 02 ).

TABELA 01: Parâmetros que apresentam alteração nas análises Físico-Químico na Captação da Represa do 14.

\begin{tabular}{cccccccc}
\hline Parâmetro & Unidade & $\begin{array}{c}\text { Data de } \\
\text { Realização } \\
\text { do Ensaio }\end{array}$ & $\begin{array}{c}\text { LQ } \\
\text { Incerteza } \\
\text { do } \\
\text { Método }\end{array}$ & $\begin{array}{c}\text { Portaria } \\
\mathbf{2 . 2 9 1 4} \text { do } \\
\text { Ministério da } \\
\text { Saúde }\end{array}$ & $\begin{array}{c}\text { Metodologia de } \\
\text { Referência }\end{array}$ & Resultado \\
\hline $\begin{array}{c}\text { Coliformes } \\
\text { Totais }\end{array}$ & $\begin{array}{c}\text { NMP/100m } \\
\text { Cor Aparente }\end{array}$ & Nov/13 & 1,1 & - & Ausência & SM9221 & $6,8 \times 10^{2}$ \\
$\begin{array}{c}\text { Escherichia } \\
\text { coli }\end{array}$ & $\begin{array}{c}\text { NMP/100m } \\
\text { L }\end{array}$ & & 1 & 0,5 & 15 & SM2120B & 58 \\
Ferro total & MG/L & 1,1 & - & Ausência & SM9221 & $4,0 \times 10^{2}$ \\
\hline
\end{tabular}

Fonte: Laboratório Eco System.

TABELA 02: Parâmetros que apresentam alteração nas análises Físico-Químico na Captação do Rio Acima

\begin{tabular}{cccccccc} 
Parâmetro & Unidade & $\begin{array}{c}\text { Data de } \\
\text { Realização } \\
\text { do Ensaio }\end{array}$ & LQ & $\begin{array}{c}\text { Incerteza } \\
\text { do } \\
\text { Método }\end{array}$ & $\begin{array}{c}\text { Portaria } \\
\mathbf{2 . 2 9 1 4} \text { do } \\
\text { Ministério da } \\
\text { Saúde }\end{array}$ & $\begin{array}{c}\text { Metodologia de } \\
\text { Referência }\end{array}$ & Resultado \\
\hline $\begin{array}{c}\text { Coliformes } \\
\text { Totais }\end{array}$ & $\begin{array}{c}\text { NMP/100m } \\
\text { Cor Aparente }\end{array}$ & Nov/13 & 1,1 & - & Ausência & SM9221 & $7,8 \times 10^{2}$ \\
$\begin{array}{c}\text { Escherichia } \\
\text { coli }\end{array}$ & NMP/100m & & 1 & 0,5 & 15 & SM2120B & 71 \\
\hline
\end{tabular}

Fonte: Laboratório Eco System. 


\section{Revista Nacional de}

Gerenciamento de Cidades

$\mathrm{Na}$ captação da represa do 14 , estão acima do limite estabelecido os Coliformes Totais, a Cor Aparente e Escherichia coli. Na captação do Córrego do Rio Acima, estão acima dos limites o Ferro Total, os Coliformes Totais, a Cor Aparente, Eschechia coli e a Turbidez.

Os Coliformes Totais e Escherichia coli são provenientes da atividade de criação de gado na bacia hidrográfica que geram microorganismos patogênicos de origem entérica, animal ou humana que são excretadas nas fezes dos indivíduos e transportadas até o curso d'água (Adaptado SOUZA et.al., 1983).

A cor aparente e a turbidez se explicam por substâncias dissolvidas ou em estado coloidal, na maioria dos casos de natureza orgânica, sendo sua presença aumentada em períodos chuvosos, período em que as amostras foram recolhidas.

A alta presença de ferro ocorre pela dissolução de compostos ferrosos de solos arenosos presentes no entorno. Sem o tratamento adequado, essas substâncias se tornam vetores de várias doenças para o ser humano (Adaptado de CETESB, 2014).

Após o tratamento recebido nas duas estações, verificou-se a eliminação dos riscos e a padronização de acordo com a portaria do Ministério da Saúde.

\section{CONCLUSÕES}

O Índice de Qualidade de Águas foi concebido originalmente para avaliar a qualidade das águas não poluídas e, posteriormente, para avaliara tratabilidade da água para o consumo humano, sendo nesse trabalho utilizado como um bom indicador de mensuração da qualidade das águas captadas, tratadas e posteriormente distribuídas para consumo da população em geral.

Conclui-se que os indicadores físico-químicos utilizados neste trabalho fornecem informações distintas e complementares na avaliação da bacia do córrego do Rio Acima. Estes indicadores também contribuem para o entendimento das 


\section{Revista Nacional de}

Gerenciamento de Cidades

transformações ocorridas na qualidade das águas. Dessa forma, é possível correlacionar estes resultados às possíveis contaminações de origem antrópica carreadas para a bacia, demonstrando, assim, que é necessária uma maior harmonia entre o homem e os recursos hídricos. Este estudo alerta também para a necessidade de se respeitar os limites de mata ciliar, de fazer uso adequado do solo, de conscientizaras comunidades, além de incentivar a realização de campanhas e de projetos de preservação ambiental.

\section{REFERÊNCIAS BIBLIOGRÁFICAS}

ANA - Agência Nacional de Águas. Gestão de Bacias Hidrográficas. 2014. Disponível em: $<w w w 2 . a n a . g o v . b r>$. Acesso em: 13 ago. 2014.

BOLLMANN, Harry Alberto. Avaliação da qualidade das águas em bacias hidrográficas urbanas. In: ANDREOLI, Cleverson Vitório (Org.). Mananciais de abastecimento: planejamento e gestão: estudo de caso do altíssimo Iguaçu. Curitiba: Sanepar, Finep, 2003. P. 267-316.

BRASIL. Ministério do Meio Ambiente. Lei no 9.433, de 08 de janeiro de 1997. Institui a Política Nacional de Recursos Hídricos, cria o Sistema Nacional de Gerenciamento de Recursos Hídricos, regulamenta o inciso XIX do art. 21 da Constituição Federal, e altera o art. 1ํ da Lei no 8.001, de 13 de março de 1990, que modificou a Lei oㅜ 7.990, de 28 de dezembro de 1989. Diário Oficial da União. 72 p.

BRASIL. Ministério do Meio Ambiente. Resolução no 32, de 15 de janeiro de 2003. Diário Oficial da União. Brasília, 17 jan. 2003.

CETESB - COMPANHIA AMBIENTAL DO ESTADO DE SÃO PAULO. Ferro. 2014. Disponível em: $<$ http://www.cetesb.sp.gov.br/userfiles/file/agua/aguas-superficiais/aguas-

interiores/variaveis/aguas/variaveis_quimicas/ferro.pdf>. Acesso em: 15 ago. 2014.

CHRISTOFOLETTI, Antonio. Geomorfologia. 2. ed. São Paulo: Edgard Blücher, 1980. 185 p.

BARUQUI, Alfredo Melhemet al. Levantamento de reconhecimento de média intensidade dos solos da zona Campos da Vertentes - MG. Rio de Janeiro: Embrapa Solos, 2006. 328 p.

MACIEL JÚNIOR, Orlando Campos. Estudo de movimentos de subsistência na região central de São João del-Rei - MG. 2001. 86 f. Dissertação (Mestrado) - Curso de Mestrado em Engenharia Civil, Departamento de Engenharia Civil, Universidade Federal de Viçosa, Viçosa, 2001.

PERINI, Brayam Luiz Batista; ZIERHUT, Elton João; SELLIN, Noeli; Índice de Qualidade de Água IQA de Bacias Hidrográficas do Município de São Francisco do Sul - SC. Anais do III Congresso Brasileiro de Gestão Ambiental. Goiânia. p. 1-5. 2012. 


\section{Revista Nacional de}

SAAD, Antonio Roberto et al. Índice de Qualidade de Água - IQA do Reservatório do Tanque Grande, Município de Guarulhos, Estado de São Paulo, Brasil: 1990-2006. Revista Ung: Geociências, Guarulhos, v. 6, n. 1, p.118-133, 2007.

SILVEIRA, Telma de Assis; GUANDIQUE, Manuel Enrique Gamero. Água: Patrimônio Natural da Vida. 2006. Disponível em: <www.sorocaba.unesp.br/noticias/artigos>. Acesso em: 10 ago. 2014.

SOUZA, Luiz Carlos et al. Bactérias coliformes totais e coliformes de origem fecal em águas usadas na dessedentação de animais. Revista de Saúde Pública, São Paulo, v. 17, n. 2, p.1-17, 1983.

TEIXEIRA, Wilson et al (org). Decifrando a Terra. São Paulo: Companhia Editora Nacional, 2008. $558 \mathrm{p}$. 